\title{
Preservatives and their role in Pharma and Clinical Research
}

Iman Himoudy

Department of medical Science, University Of Medical Science And Technology

*Corresponding author: Iman Himoudy, Department of medical Science, University Of Medical Science And Technology, Ph No : 0570686424, ,E-mail : Dr.iman.himoudy@gmail.com

Citation: Iman Himoudy (2016). Preservatives and their role in Pharma and Clinical Research Int J Pharm Sci \& Scient Res.2:4, 134-151.

Copyright: (c) 2016 Iman Himoudy. This is an open-access article distributed under the terms of the Creative Commons Attribution License, which permits unrestricted use, distribution, and reproduction in any medium, provided the original author and source are credited..

\section{Received June 26, 2016; Accepted September 19, 2016; Published September 29, 2016}

\section{Introduction}

Preservatives are substances that commonly added to various foods and pharmaceutical products in order to prolong their shelf life. The addition of preservatives to such products, especially to those that have higher water content, is essential for avoiding alteration and degradation by microorganisms during storage.

The British pharmacopoeia (BP) stated that the addition of antimicrobial preservatives to radio-pharmaceutical preparations in multi dose containers is not obligatory unless their addition is prescribed in the monograph.

\section{classification of preservative}

Preservatives are classified into two main classes:

Antimicrobial preservative and antioxidant.

Antimicrobial preservatives are included in the preparations to kill or to inhibit the growth of micro-organisms inadvertently introduced during manufacture or use. They are used in sterile preparations such as eye drops and multi dose injections to maintain sterility during use. They may be also added to aqueous injections that cannot be sterilized in their final containers and have to be prepared using aseptic precautions. Preservatives are also used in cosmetics, foods, and non sterile pharmaceutical products such as oral liquids and creams to prevent microbial spoilage. They are not used indiscriminately, and preparations that should not contain preservatives include; injection into cerebrospinal fluids, eye or heart

Antimicrobial preservatives are classified into two main subgroups: anti-fungal preservatives and anti-bacterial preservatives. Anti-fungal preservatives include compounds such as benzoic and ascorbic acids and their salts, and phenolic compounds such as methyl, ethyl, propyl and butyl p-hydroxybenzoate (parabens). Antibacterial preservatives include compounds such as quaternary ammonium salts, alcohols, phenols, mercurial's and biguanidinesrt

\section{Antioxidants}

There are included in the pharmaceutical products to prevent deterioration from oxidation. Antioxidants are classified into 3 groups. The first group is known as true antioxidants, or antioxygen, probably inhibit oxidation by reacting with free radicals blocking the chain reaction. Examples are alkygallates butylated hydroxyanisol, butylated hydroxytoluene, nordihydroguaiaretic acid and the tocopherols. The second group consists of reducing agents; these substances have lower redox potentials than the drug or adjuvant which they are intended to protect, and are therefore, more readily oxidized. Reducing agents may act also by reacting with free radicals. Examples are ascorbic acid, the potassium and sodium salts of sulphurous acid. The third group consists of antioxidant synergists which usually have little antioxidant effect themselves but probably enhance the action of antioxidants in the first group by reacting with heavy metal ions which catalyze oxidation. Example of antioxidant synergists are citric acid, editic acid and its salts, lecithin and tartaric acid $\{1\}$.

Single preservative, but more often combinations of preservatives, are commonly used in pharmaceuticals, cosmetics, biological samples, food, wood, and plastics products to prevent alteration and degradation of the product formulations. However these preservatives may be harmful to consumer due to their tendency to induce allergic contact. Hence the simultaneous determination of these preservatives in commercial pharmaceutical products is particularly important both for quality assurance and consumer safety.

Antimicrobial preservatives have been analyzed by both microbiological and chemical methods $\{2\}$.

It is also a regulatory requirement to assess the antimicrobial efficacy of the drug product (in its final container) at the end of the product's proposed shelf-life. Activity needs to be broad spectrum, 
encompassing bacteria (Gram-positive and Gram-negative), yeasts, fungi and molds; but not viruses. An effective preservative must reduce a microbial population significantly and prevent subsequent re-growth and these effects must be both microcidal and microstatic in nature.

Combining preservatives that act synergistically may help meet performancestandards. Benzalkonium chloride (BKC) is ineffective against some strains of Pseudomonas aeruginosa, Mycobacterium and Trichophyton, but combinations with EDTA, benzyl alcohol, 2-phenylethanol or 3-phenylpropanol enhances anti-Pseudomonad activity . Synergy is also observed in combination with cetrimide, 3-cresol, chlorhexidine and organo mercurials.

Multiple use products must be protected from proliferation of adventitious contamination. That is, they must be preserved. The standard method to demonstrate preservation of a formulation is the antimicrobial efficacy test (AET). This test is a suspension

Table 1.1: Classes of Antimicrobial preservatives:

\begin{tabular}{|c|c|}
\hline Class & Chemical Structure \\
\hline $\begin{array}{l}\text { Parabens } \\
\text { Methyl paraben } \\
\text { Ethyl paraben } \\
\text { Propyl paraben } \\
\text { Butyl paraben }\end{array}$ & $\begin{array}{l}\mathrm{HO}-\mathrm{CO}_{2} \mathrm{R} \\
\mathrm{R}=\mathrm{CH}_{3} \text { Methyl paraben } \\
\mathrm{R}=\mathrm{C}_{2} \mathrm{H}_{5} \text { Ethyl parabe } \mathrm{n} \\
\mathrm{R}=\mathrm{C}_{3} \mathrm{H}_{7} \text { Fropyl paraben } \\
\mathrm{R}=\mathrm{C}_{4} \mathrm{H}_{9} \text { Butyl paraben }\end{array}$ \\
\hline $\begin{array}{l}\text { Acids and their salts } \\
\text { Benzoic acid } \\
\text { Sodium benzoate } \\
\text { Sorbic acid } \\
\text { Sodium Sorbate }\end{array}$ & 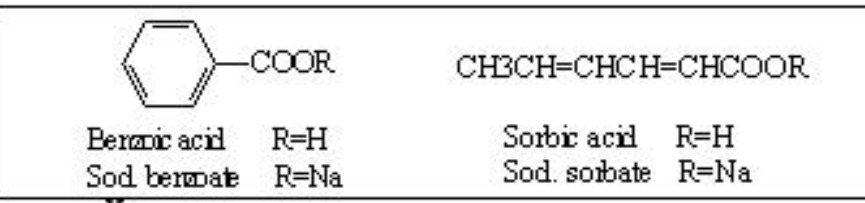 \\
\hline $\begin{array}{l}\text { Quaternary } \\
\text { Ammonium } \\
\text { Compounds } \\
\text { Cetrimide } \\
\text { Benzalkonium chloride } \\
\text { Cetylpyridinum } \\
\text { cholride } \\
\text { Benzaethonium } \\
\text { chloride }\end{array}$ & Cetim kle \\
\hline $\begin{array}{l}\text { Mercurials } \\
\text { Phenylmercuric nitrate } \\
\text { Thiomersal }\end{array}$ & $\underbrace{}_{\text {Pherglmercuic ritrate }}$ \\
\hline $\begin{array}{l}\text { Alcohols } \\
\text { Benzyl alcohol } \\
\text { Phenylethyl alcohol } \\
\text { Bronabol } \\
\text { Chlorbutanol }\end{array}$ & $\begin{array}{l}\mathrm{R}_{\mathrm{R}=\mathrm{OH} \text { Benzyl alc. }} \\
\mathrm{R}=\mathrm{CH} 2 \mathrm{OH} \text { Phenylethyl alc. Bronabol }\end{array}$ \\
\hline
\end{tabular}


Table 1.1: Cont

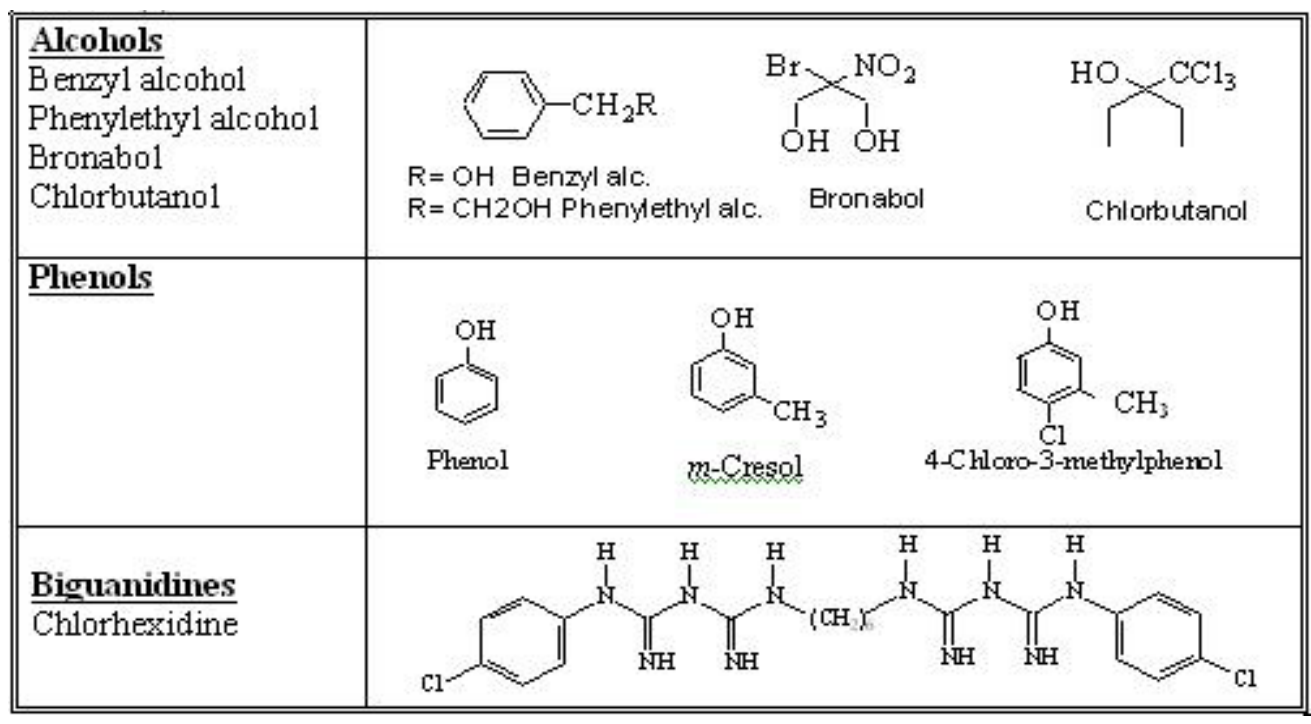

Table 1.2: Classes of Antioxidants

\begin{tabular}{l}
\hline \multicolumn{1}{|c|}{ Class } \\
\hline 1.True-Antioxidants: \\
Phenolic antioxidants: \\
Butylated hydroxyanisole \\
(BHA). \\
Butylated hydroxytolyene \\
(BHT). \\
Tert-butyl-hydroquinone \\
(TBHQ). \\
4-Hydroxymethyl-2,6-di- \\
tert-butylpheno1 (HMBP).
\end{tabular}


test, where challenge organisms are suspended in the product to be tested and their survival determined with time. A standard format for this test is to individually suspend 4 or 5 challenge organisms to a final concentration of approximately $106 \mathrm{CFU} / \mathrm{mL}$ and check for survivors at 6 hours, 24 hours, 48 hours, 7 days, 14 days and 28 days. The multiple time points allow for determination of kill rate against the organism, and the organisms are selected to provide a range of responses to the preservative system. The use of these intervals may allow the data to be used in all regulatory regions. $\{3\}$

The antimicrobial effectiveness test is one that can provide a great deal of information on a stability program. While each organism's response might not be illuminating, it is likely that at least one of the organisms will provide useful information. Unlike the chemical assay for identity and for concentration of the preservative, the AET evaluates the biological activity of the entire formulation. It is clearly a superior test for preservative activity to those available by HPLC. Unfortunately there seems to be a perception that chemical stability of the preservative moiety is directly related to the microbial performance. While this is generally true, the exceptions can lead to spectacular situations for the head of the microbiology group. $\{4\}$

Ophthalmic preparations (eye preparations) are sterile, liquid, semi-solid, or solid preparations that may contain one or more active pharmaceutical ingredient(s) intended for application to the conjunctiva, the conjunctival sac or the eyelids.

The choice of base and any excipients used for the preparation of ophthalmic preparations must be proven through product development studies not to affect adversely either the stability of the final product or the availability of the active ingredients at the site of action. The addition of coloring agents is not recommended.

Unless the active ingredient itself has antimicrobial activity, ophthalmic preparations supplied as multi-dose preparations may include a suitable antimicrobial agent. The antimicrobial activity should remain effective throughout the entire period of use.

The different categories of ophthalmic preparations include drops consisting of emulsions, solutions or suspensions, and ointments. The manufacturing processes should meet the requirements of Good Manufacturing Practices, especially with regard to crosscontamination. The following information is intended to provide very broad guidelines concerning the main steps to be followed during production, indicating those that are the most important.

Throughout manufacturing, certain procedures should be validated and monitored by carrying out appropriate in-process controls. These should be designed to guarantee the effectiveness of each stage of production. In-process controls during production of ophthalmic preparations should include monitoring environmental conditions (especially with respect to particulate and microbial contamination), pyrogens (use of a limulus amoebocyte lysate (LAL) test may be advantageous), $\mathrm{pH}$ and clarity of solution, and integrity of container (absence of leakage, etc.). Appropriate limits should be set for the particle size of the active ingredient(s).

It is essential that ophthalmic preparations are sterile. An aseptic manufacturing process is usually employed when the dosage form does not allow routine sterilization methods to be used. $\{5\}$

\section{Justification:}

It's imperative that the medicine given to the patient is stable physically, chemically and microbiologically throughout its shelf life. A chemical present in the formulation as a preservative may also decompose and their decomposition may influence the physical and chemical stability of the drug .Safe and microbiologically stable drugs should not suffer from any microbiological attack and should meet the standard with respect to sterility or lack of contamination which is claimed on the label.

Ophthalmic preparation must be sterile, an antimicrobial substances as preservative are added to prevent contamination to the formulation during storage and use. Risk of contamination is more encountered in multiple doses than in unit dose formulations and hazardous to the patient.

\section{General objectives:}

To determine the effectiveness of preservative in multi-dose Timolol eye drops.

Specific objectives:

- To determine the concentration of timolol in ophthalmic eye drops and to see if it complies with label or not.

- To determine efficiency of preservative from first day, 7th and 14th day and 28th

- To determine the magnitude and pattern of microbial contamination of multi -dose eye drops.

- To investigate the compliance of the ophthalmic preparation with respect to the acidity and alkalinity.

\section{Literature Review:}

Antimicrobial preservatives are substances added to non sterile dosage forms to protect them from microbiological growth or from microorganisms that are introduced inadvertently during or subsequent to the manufacturing process. In the case of sterile article packaged in multiple-dose containers, antimicrobial preservatives are added to inhibit the growth of microorganisms that may be introduced $\{5\}$.

Antimicrobial preservatives should not be used as substitute for good manufacturing practices or solely to reduce the viable microbial population of non sterile product or control the prestrilization bioburden of multidose formulations during manufacturing $\{6\}$.

Several studies has been published about preservative in eye drops.

The importance of eye drops being sterile on use has been increasingly emphasized in recent decades consequently, aseptic preparation, sterilization and addition of preservative are three steps in consequence in their manufacture.

Demand of sterility of eye drops have been introduced into most pharmacopeia during the past 20 years $\{7\}$.

Data are presented on the relative antimicrobial activities of seven commonly used chemical compounds that are used for preserving ophthalmic drug solutions from Pseudomonas and Proteus contaminations. In testing the compounds against 26 
strains of Pseudomonas aeruginosa and four species of Proteus in a simple buffer solution, in the absence of an ophthalmic drug, the order of activity of the agents from high to low were found to follow the pattern: Benzalkonium chloride $>$ phenylmercuric nitrate $>$ phenol or chlorobutanol $>$ parabens $>$ thimerosal $>$ phenylethyl alcohol. When the compounds were tested against some of the organisms in distilled water the order of activity from high to low was found to be as follows: Benzalkonium chloride $>$ phenylmercuric nitrate $>$ chlorobutanol $>$ phenol or thimerosal $>$ parabens $>$ phenylethyl alcohol. When the preservatives were added to aqueous solutions of ophthalmic drugs experimentally contaminated with Pseudomonas aeruginosa, the order of activity of the compounds was: Benzalkonium chloride $>$ chlorobutanol $>$ phenol $>$ parabens $>$ phenylmercuric nitrate $>$ phenylethyl alcohol or thimerosal. Several suggestions are given for the selection of a suitable preserving agent for ophthalmic drugs and certain procedures to be followed in the formulation of solutions under practical conditions in hospital and pharmacy routine $\{8\}$.

To assess the suitability of benzalkonium chloride as a preserving agent for potential contact lens fluids, the authors tested its antimicrobial efficiency at various $\mathrm{pH}$ values, in the presence of viscosity modifiers (hydroxyethylcellulose, polyvinylpyrrolidone, polyacrylamide) and also in combination with other preserving agents. The diffusion test and the suspension test were used as test methods. The efficiency of benzalkonium chloride depends upon the $\mathrm{pH}$ value of the solution and upon the concentrations of the viscosity modifiers. No better results were achieved by combination with phenylethanol and chlorobutanol. Formulations for potential contact lens fluids were indicated, the appropiateness of which is viewed in microbiological perspective $\{9\}$.

The study was conducted to examine the antimicrobial activity and the preservative efficacy of a novel preservative solution containing sodium hydroxymethyl glycinate (SHMG) and edetate disodium (EDTA), which is used for preservation of some commercial ophthalmic formulations. Methods: In vitro susceptibility assays were performed against several gram-positive (Staphylococcus aureus, Staphylococcus epidermidis, and Bacillus cereus) and gram-negative (Escherichia coli and Pseudomonas aeruginosa) bacteria representative of the microbial flora of epithelial surfaces or colonizing the conjunctiva, as well as against Candida albicans and Aspergillus niger. Using different concentrations of SHMG alone or in combination with EDTA, the minimal inhibitory and microbicidal concentrations against these organisms were assessed. In addition, 8 brands of multidose eye drops containing $0.002 \%$ SHMG and $0.1 \%$ EDTA as preservative were tested for antimicrobial activity using the antimicrobial effectiveness test recommended by the international pharmacopoeias. The results showed that the minimal inhibitory and bactericidal/ fungicidal concentration values of SHMG ranged from $0.0025 \%$ to $0.0125 \%$ for bacteria and from $0.125 \%$ to $0.50 \%$ for mold and yeast. Susceptibility testing demonstrated that the addition of EDTA substantially increased the SHMG activity against all bacterial and fungal strains. The preservative effectiveness test was applied to commercial eye drops. All the drop solutions met the criteria reported by the U.S. Pharmacopeia for parenteral and ophthalmic preparations. All products also satisfied the major acceptance criteria of the European Pharmacopeia with respect to the antifungal activity. As regard the antibacterial activity, the lessstringent criteria of the European Pharmacopeia were fulfilled. The authors concluded that the present study demonstrates the efficacy of a novel preservative for ophthalmic solutions (SHMG/ EDTA) and its activity in protecting selected commercial artificial tears against microbial contamination. $\{10\}$

Preservatives are a legal requirement for eye drops in multidose containers. Moreover, they are necessary for stabilization and intraocular penetration for a number of ophthalmic preparations. Most preservatives act in a relatively unspecific manner as detergents or by oxidative mechanisms and thereby cause side effects at the ocular surface. They may also affect the lens, trabecular meshwork and the retina. Benzalkonium chloride is the most commonly used preservative in ophthalmology and is more toxic than other or newer preservatives, such as polyquaternium-1

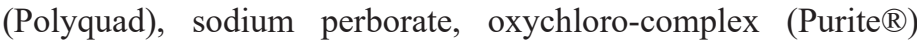
and SofZia. Preservative-free topical medication is highly recommended for patients with ocular surface disease, frequent eye drop administration, proven allergy to preservatives and contact lens wear. $\{11\}$

\section{Methodology:}

Method 1: Antimicrobial effectiveness testing:

\section{TEST ORGANISMS:}

Use cultures of the following microorganisms: Candida albicans (ATCC No. 10231), Aspergillus niger (ATCC No. 16404), Escherichia coli (ATCC No. 8739), Pseudomonas aeruginosa (ATCC No. 9027), and Staphylococcus aureus (ATCC No. 6538). The viable microorganisms used in the test must not be more than five passages removed from the original ATCC culture. For purposes of the test, one passage is defined as the transfer of organisms from an established culture to fresh medium. All transfers are counted. In the case of organisms maintained by seedlot techniques, each cycle of freezing, thawing, and revival in fresh medium is taken as one transfer. A seed-stock technique should be used for long-term storage of cultures. Cultures received from the ATCC are resuscitated according to directions. If grown in broth, the cells are pelleted by centrifugation. Resuspend in $1 / 20$ th the volume of fresh maintenance broth, and an equal volume of $20 \%$ (v/v in water) sterile glycerol was added. Cells grown on agar are scraped from the surface into the $10 \%$ glycerol broth. Small aliquots of the suspension are dispensed into sterile vials. The vials are stored in liquid nitrogen or in a mechanical freezer at no more than 50C. When a fresh seed-stock vial is required, it is removed and used to inoculate a series of working cultures. These working cultures are then be used periodically (each day in the case of bacteria and yeast) to start the inoculums culture.

\section{MEDIA:}

All media used in the test are pretested for growth promotion. Using the microorganisms indicated above under Test Organisms.

\section{PREPARATION OF INOCULUM:}

Preparatory to the test, inoculate the surface of a suitable volume 
of solid agar medium from a recently revived stock culture of each of the specified microorganisms. The culture conditions for the inoculum culture are described in Table 3.1 in which the suitable media are Soybean-Casein Digest or Sabouraud Dextrose Agar Medium

To harvest the bacterial and C. albicans cultures, sterile saline TS is used, washing the surface growth, collecting it in a suitable vessel, and adding sufficient sterile saline TS to obtain a microbial count of about $1 \times 108$ colony-forming units (cfu) per $\mathrm{mL}$. To harvest the cells of A. niger, a sterile saline TS containing $0.05 \%$ of polysorbate 80 is used, and sufficient sterile saline TS is added to obtain a count of about $1 \times 108$ cfu per $\mathrm{mL}$

Alternatively, the stock culture organisms may be grown in a suitable liquid medium (i.e., Soybean-Casein Digest Broth or Sabouraud Dextrose Broth) and the cells harvested by centrifugation, then washed and resuspended in sterile saline TS to obtain a microbial count of about $1 \times 108 \mathrm{cfu}$ per $\mathrm{mL}$. [ NOTE - The estimate of inoculum concentration is performed by turbidimetric measurements for the challenge microorganisms. Refrigerate the suspension if it is not used within 2 hours. ]

The number of cfu per $\mathrm{mL}$ in each suspension is determined, using the conditions of media and microbial recovery incubation times listed in Table 3.1 to confirm the initial cfu per mL estimate. This value serves to calibrate the size of inoculum used in the test. The bacterial and yeast suspensions are to be used within 24 hours of harvest, but the fungal preparation may be stored under refrigeration for up to 7 days

\section{PROCEDURE:}

The test was conducted in five original containers if sufficient volume of product is available in each container and the product container can be entered aseptically (i.e., needle and syringe through an elastomeric rubber stopper), Inoculate each container with one of the prepared and standardized inoculum, and mix. The volume of the suspension inoculum used is between $0.5 \%$ and $1.0 \%$ of the volume of the product. The concentration of test microorganisms that is added to the product (Categories 1, 2, and 3 ) are such that the final concentration of the test preparation after inoculation is between $1 \times 105$ and $1 \times 106 \mathrm{cfu}$ per $\mathrm{mL}$ of the product. For Category 4 products (antacids) the final concentration of the test preparation after inoculation is between $1 \times 103$ and $1 \times$ 104 cfu per $\mathrm{mL}$ of the product

The initial concentration of viable microorganisms in each test preparation is estimated based on the concentration of microorganisms in each of the standardized inoculum as determined by the plate-count method

Incubate the inoculated containers at $22.5 \pm 2.5 \mathrm{C}$. Sample each container at the appropriate intervals specified in Table 3.1 Record any changes observed in appearance at these intervals. Determine by the plate-count procedure the number of cfu present in each test preparation for the applicable intervals Incorporate an inactivator (neutralizer) of the specific antimicrobial in the plate count or in the appropriate dilution prepared for plating. These conditions are determined in the validation study for that sample based upon the conditions of media and microbial recovery incubation times listed in Table 3.1. Using the calculated concentrations of cfu per $\mathrm{mL}$ present at the start of the test, calculate the change in $\log 10$ values of the concentration of cfu per $\mathrm{mL}$ for each microorganism at the applicable test intervals, and express the changes in terms of log reductions

\section{CRITERIA FOR ANTIMICROBIAL EFFECTIVENESS:}

The requirements for antimicrobial effectiveness are met if the criteria specified under Table 3.2 are met No increase is defined as not more than $0.5 \log 10$ unit higher than the previous value measured

Method 2: Investigation of \%content of API by Chemical assay:

Dilute a volume containing the equivalent of $25 \mathrm{mg}$ of timolol to $50 \mathrm{~mL}$ with water. To $5 \mathrm{~mL}$ add $15 \mathrm{~mL}$ of carbonate buffer $\mathrm{pH} 9.7$ and extract with three $20-\mathrm{mL}$ quantities and one $10-\mathrm{mL}$ quantity of toluene. Wash each extract successively with the same $10 \mathrm{~mL}$ volume of carbonate buffer $\mathrm{pH} 9.7$, combine the toluene extracts and extract with four $20-\mathrm{mL}$ quantities of $0.05 \mathrm{M}$ sulfuric acid. Combine the extracts, dilute to $100 \mathrm{~mL}$, filter and measure the absorbance at the maximum at $295 \mathrm{~nm}$, Appendix II B, using in the reference cell a solution prepared by treating $5 \mathrm{~mL}$ of water in the same manner, beginning at the words 'add $15 \mathrm{~mL} . .$. '. Calculate the content of $\mathrm{C} 13 \mathrm{H} 24 \mathrm{~N} 4 \mathrm{O} 3 \mathrm{~S}$ taking 279 as the value of $\mathrm{A}(1 \%, 1$ $\mathrm{cm})$ at the maximum at $295 \mathrm{~nm}$.

Specification:

The eye drops comply with the requirements stated under Eye Preparations and with the following requirements.

Content of timolol, $\mathrm{C} 13 \mathrm{H} 24 \mathrm{~N} 4 \mathrm{O} 3 \mathrm{~S}$, must be the range of 90.0 to $110.0 \%$ of the stated amount.

$\mathrm{pH}$ determination of timolol eye drops:

Specification limit according to $\mathrm{BP}$ is the $\mathrm{pH}$ range of 6.5 to 7.5

Equipments and materials:

For antimicrobial effectiveness test:

Loop

Plate

Flame

Incubator (EN055)

Oven (EN400)

Media (blood agar and nutrient agar)

McFarland standard (for standardization the concentration of bacterial growth)

For chemical assay:

Apparatus:

Measuring cylinders $100 \mathrm{ml}$

Beakers $\quad 500 \mathrm{ml}$

Volumetric flasks $\quad 50 \mathrm{ml}, 100 \mathrm{ml}$

Separating funnels $\quad 500 \mathrm{ml}$

Pipettes $5 \mathrm{ml}$

Funnels 


\begin{tabular}{|l|l|l|l|l|}
\hline Organism & Suitable Medium & $\begin{array}{l}\text { Incubation } \\
\text { Temperature }\end{array}$ & $\begin{array}{l}\text { Inoculum } \\
\text { Incubation } \\
\text { Time }\end{array}$ & $\begin{array}{l}\text { Microbial Recov- } \\
\text { ery } \\
\text { Incubation Time }\end{array}$ \\
\hline $\begin{array}{l}\text { Escherichia coli } \\
\text { (ATCC No. 8739) }\end{array}$ & $\begin{array}{l}\text { Soybean-Casein Digest } \\
\text { Broth; } \\
\text { Soybean-Casein Digest } \\
\text { Agar }\end{array}$ & $32.5 \pm 2.5 \nmid$ & 18 to 24 hours & 3 to 5 days \\
\hline $\begin{array}{l}\text { Pseudomonas aerugi- } \\
\text { nosa } \\
\text { (ATCC No. 9027) }\end{array}$ & $\begin{array}{l}\text { Soybean-Casein Digest } \\
\text { Broth; } \\
\text { Soybean-Casein Digest } \\
\text { Agar }\end{array}$ & $32.5 \pm 2.5 \nmid$ & 18 to 24 hours & 3 to 5 days \\
\hline $\begin{array}{l}\text { Staphylococcus aureus } \\
\text { (ATCC No. 6538) }\end{array}$ & $\begin{array}{l}\text { Soybean-Casein Digest } \\
\text { Broth; } \\
\text { Soybean-Casein Digest } \\
\text { Agar }\end{array}$ & $32.5 \pm 2.5 \nmid$ & 18 to 24 hours & 3 to 5 days \\
\hline $\begin{array}{l}\text { Candida albicans } \\
\text { (ATCC No. 10231) }\end{array}$ & $\begin{array}{l}\text { Sabouraud Dextrose Agar; } \\
\text { Sabouraud Dextrose Broth }\end{array}$ & $22.5 \pm 2.5 \nmid$ & 44 to 52 hours & 3 to 5 days \\
\hline $\begin{array}{l}\text { Aspergillus niger } \\
\text { (ATCC No. 16404) }\end{array}$ & $\begin{array}{l}\text { Sabouraud Dextrose Agar; } \\
\text { Sabouraud Dextrose Broth }\end{array}$ & $22.5 \pm 2.5 \nmid$ & 6 to 10 days & 3 to 7 days \\
\hline
\end{tabular}

Table3.1. Culture Conditions for Inoculums' Preparation

\subsubsection{CRITERIA FOR ANTIMICROBIAL EFFECTIVENESS}

The requirements for antimicrobial effectiveness are met if the criteria specified under Table 3.2 are met No increase is defined as not more than $0.5 \log 10$ unit higher than the previous value measured

Table 3.2. Criteria for Tested Microorganisms

\section{For Category 1 Products}

\begin{tabular}{|r|l|}
\hline Bacteria: & $\begin{array}{r}\text { Not less than } 1.0 \text { log reduction from the initial calculated count at } 7 \text { days, not less than } \\
3.0 \log \text { reduction from the initial count at } 14 \text { days, and no increase from the } 14 \text { days' } \\
\text { count at } 28 \text { days }\end{array}$ \\
\hline Yeast $\begin{array}{r}\text { and } \\
\text { Molds: }\end{array}$ & No increase from the initial calculated count at 7,14, and 28 days \\
\hline
\end{tabular}

3.2 Method 2: Investigation of \%content of API by Chemical assay 
Stands

Double beam UV spectrophotometer (UV-1800 shimadzu)

PH meter (WTW 523)

Filter paper (waltman)

Chemicals:

Carbonate buffer pH 9.7 (consist of $\mathrm{NaHCO} 3$ and $\mathrm{Na} 2 \mathrm{CO} 3$ )

Toluene

$0.05 \mathrm{M}$ sulfuric acid

Distilled Water

For pH determination:

pH meter (WTW , 523)

Beakers

Plastic water bottles

\section{Results:}

4.1. Determination of percent content of API in timolol eye drops:

The percent content of API in timolol eye drops was determined uses the procedure described under methodology above .The results are presented in the following tables.

\subsection{Calculation for chemical assay:}

Carbonate buffer PH 9.7 consist of:

\section{$8.4 \mathrm{~g}$ of $\mathrm{NaHCO} 3$}

$10.6 \mathrm{~g}$ of $\mathrm{Na} 2 \mathrm{CO} 3$

Dissolved in distilled water and dilute volume to $500 \mathrm{ml}$ with

Table 4.1: determination of timolol in the eye drops at day zero.

\begin{tabular}{|l|l|l|}
\hline & Sample ID & WL295.0 \\
\hline 1 & Timolol & 0.67365 \\
\hline 2 & Timolol & 0.67419 \\
\hline 3 & Timolol & 0.67393 \\
\hline
\end{tabular}

Average: $\mathrm{Abs}=0.673923$

$\%$ content was found to be $96.6 \%$

Table 4.2: determination of timolol in the eye drops at day seven.

\begin{tabular}{|l|l|l|}
\hline & Sample ID & WL295.0 \\
\hline 1 & Timolol & 0.69019 \\
\hline 2 & Timolol & 0.68918 \\
\hline 3 & Timolol & 0.68790 \\
\hline
\end{tabular}

Average: $\mathrm{Abs}=0.6890$

Percent content was found to be $98.7 \%$
Table 4.3: determination of timolol in the eye drops at day 14.

\begin{tabular}{|l|l|l|}
\hline & $\begin{array}{l}\text { Sample } \\
\text { ID }\end{array}$ & WL295.0 \\
\hline 1 & Timolol & 0.69780 \\
\hline 2 & Timolol & 0.69890 \\
\hline 3 & Timolol & 0.69888 \\
\hline
\end{tabular}

Average: $\mathrm{Abs}=0.69852$

Percent content was found to be $100.1 \%$

Table 4.4: determination of timolol in the eye drops at day 28

\begin{tabular}{|l|l|l|}
\hline & Sample ID & WL295.0 \\
\hline 1 & Timolol & 0.78905 \\
\hline 2 & Timolol & 0.79132 \\
\hline 3 & Timolol & 0.79137 \\
\hline
\end{tabular}

Average: $\mathrm{Abs}=0.7905$

Percent content was found to be $113.3 \%$

Table 4.5: determination of timolol in the eye drops after 28 days.

\begin{tabular}{|l|l|l|}
\hline & Sample ID & WL295.0 \\
\hline 1 & Timolol & 0.82953 \\
\hline 2 & Timolol & 0.82790 \\
\hline 3 & Timolol & 0.82799 \\
\hline
\end{tabular}

Average: Abs $=0.82847$

Percent content was found to be 118.7

distilled water.

$0.05 \mathrm{M} \mathrm{H} 2 \mathrm{SO} 4$

$\mathrm{M}=\mathrm{C} * \mathrm{~d} * 10 / \mathrm{MWT}$

$98 * 1.84 * 10 / 98.08=18.38$

$\mathrm{M} 1 * \mathrm{~V} 1=\mathrm{M} 2 * \mathrm{~V} 2$

$18.38 * \mathrm{~V} 1=0.05 * 500$

So $\mathrm{V} 1=1.4 \mathrm{ml}$

Where M1, M2 = molarities

$$
\mathrm{V} 1, \mathrm{~V} 2=\text { volumes }
$$

Composition of eye drops:

Each ml contains:

Timolol (maleate) $\quad$ B.P $\quad 5 \mathrm{mg}$

BAK B.P $1 \mathrm{mg}$

$1 \mathrm{ml} \ldots \ldots . . .0 .005 \mathrm{~g}$ of timolol 
$\mathrm{Xml}$ . $.0 .025 \mathrm{~g}$ of timolol

So $5 \mathrm{ml}$ of timolol eye drops needed for each chemical assay.

Theoretical concentration $=0.025 / 50 * 5 / 100$

$$
=0.000025 \mathrm{~g} / \mathrm{ml}
$$

Con $=$ Abs /theoretical con $*$ A $(1 \%)$

$\%$ content of timolol in day zero:

$0.673923 / 0.000025 * 279=96.61 \%$

$\%$ content of timolol in day seven:

$0.6890 / 0.000025 * 279=98.7 \%$
$\%$ content of timolol in day 14 :

$0.69852 / 0.000025 * 279=100.1 \%$

$\%$ content of timolol in day 28 :

$0.7905 / 0.000025 * 279=113.3 \%$

$\%$ content of timolol after 28 days:

$0.82847 / 0.000025 * 279=118.7 \%$

Discussion, Conclusion and Recommendation:

Discussion:

The function of the preservative is to preserve the eye drops to ensure the sterility over the course of several weeks and sometimes month (usually less than a month). So the preservative are not

Table 4.6: Percent content of API

\begin{tabular}{|l|l|}
\hline Analysis days & \% content \\
\hline Day zero & $96.61 \%$ \\
\hline Day seven & $98.7 \%$ \\
\hline Day 14 & $100.1 \%$ \\
\hline Day 28 & $113.3 \%$ \\
\hline After 28 day & $118.7 \%$ \\
\hline
\end{tabular}

The results indicate that the percent of API content are within the officially specified range up to the 14th day of opening the container. After that the result falls out of this range.

Table 4.7: Bacterial effectiveness test result:

\begin{tabular}{|l|l|l|l|l|l|l|l|l|}
\hline Bactria & $\begin{array}{l}\text { Ophthalmic } \\
\text { eye drops }\end{array}$ & 0 & $6 \mathrm{hrs}$ & $24 \mathrm{hrs}$ & $7 \mathrm{~d}$ & $14 \mathrm{~d}$ & $28 \mathrm{~d}$ & After 28d \\
\hline E.COLI & - & - & - & - & - & - & - & 12 \\
\hline S.aureus & - & - & - & - & - & - & - & $>300$ \\
\hline Pseudomonas & - & - & - & - & - & - & - & $>300$ \\
\hline Fungi Candida & - & - & - & - & - & - & - & $>300$ \\
\hline
\end{tabular}

Table 5.1.3.-1. - Parenteral and ophthalmic preparations

\begin{tabular}{lcccccc}
\hline & \multicolumn{6}{c}{ Log reduction } \\
\cline { 2 - 7 } & & $\mathbf{6 ~ h}$ & $\mathbf{2 4} \mathbf{~ h}$ & $\mathbf{7 ~ d}$ & $\mathbf{1 4} \mathbf{~ d}$ & $\mathbf{2 8 ~ d}$ \\
\hline Bacteria & A & 2 & 3 & - & - & NR $^{*}$ \\
& B & - & 1 & 3 & - & NI** \\
\hline Fungi & A & - & - & 2 & - & NI \\
& B & - & - & - & 1 & NI \\
\hline
\end{tabular}

*NR: no recover

${ }^{* *} \mathrm{NI}$ : no increase

Concentration of bacteria $=1 * 10 \sim 8$

Table 4.8: Criteria for antimicrobial effectiveness (BP)

Loop diameter 0.5 micro litter

International Journal of Pharma Sciences and Scientific Research An open Access Journal

Volume 2 Issue 4, September 2016 
Table 4.9: Criteria for antimicrobial effectiveness (USP):

For category 1 products (ophthalmic eye drops)

\begin{tabular}{|l|l|}
\hline Bacteria & $\begin{array}{l}\text { Not less than } 1.0 \text { log reduction from the initial calculated count at } 7 \text { day, not } \\
\text { less than } 3.0 \text { log reduction from the initial count at } 14 \text { days, and no increase } \\
\text { from the } 14 \text { days count at } 28 \text { days. }\end{array}$ \\
\hline Yeast and mold & No increase from the initial calculated count at 7,14 , and 28 days. \\
\hline
\end{tabular}

The results indicate that the antimicrobial effectiveness in the sample lies within the limits stated by BP and USP up to the 28th day from opening the container. Beyond the 28th day the effect falls out of range .As observed in table 4.7 microbial growth rate was very high after the 28 th day of opening the product container.

Figure 4.1: Effectiveness of preservative on E.coli :

Media (1)

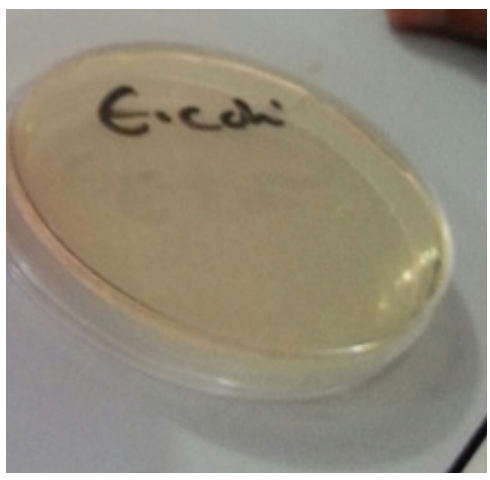

Day zero

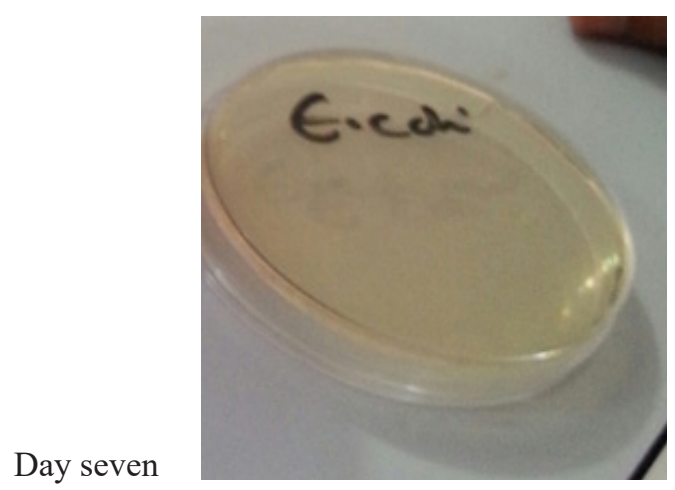

Day 14

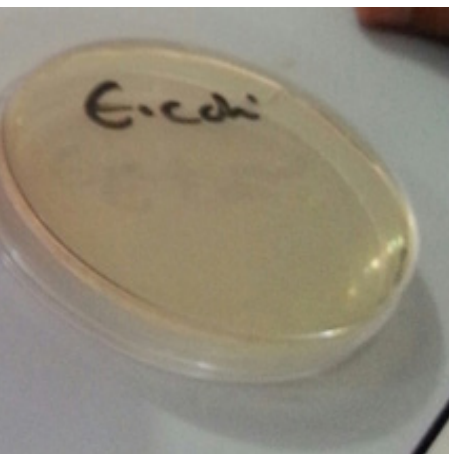

Media (2)
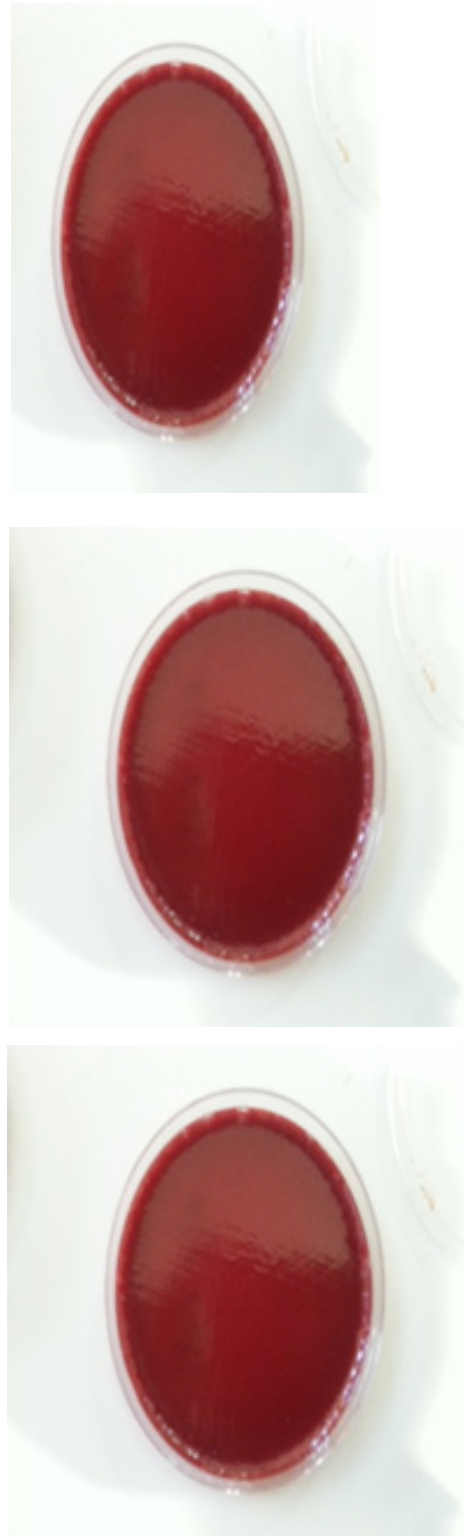
Figure 4.1 (cont):
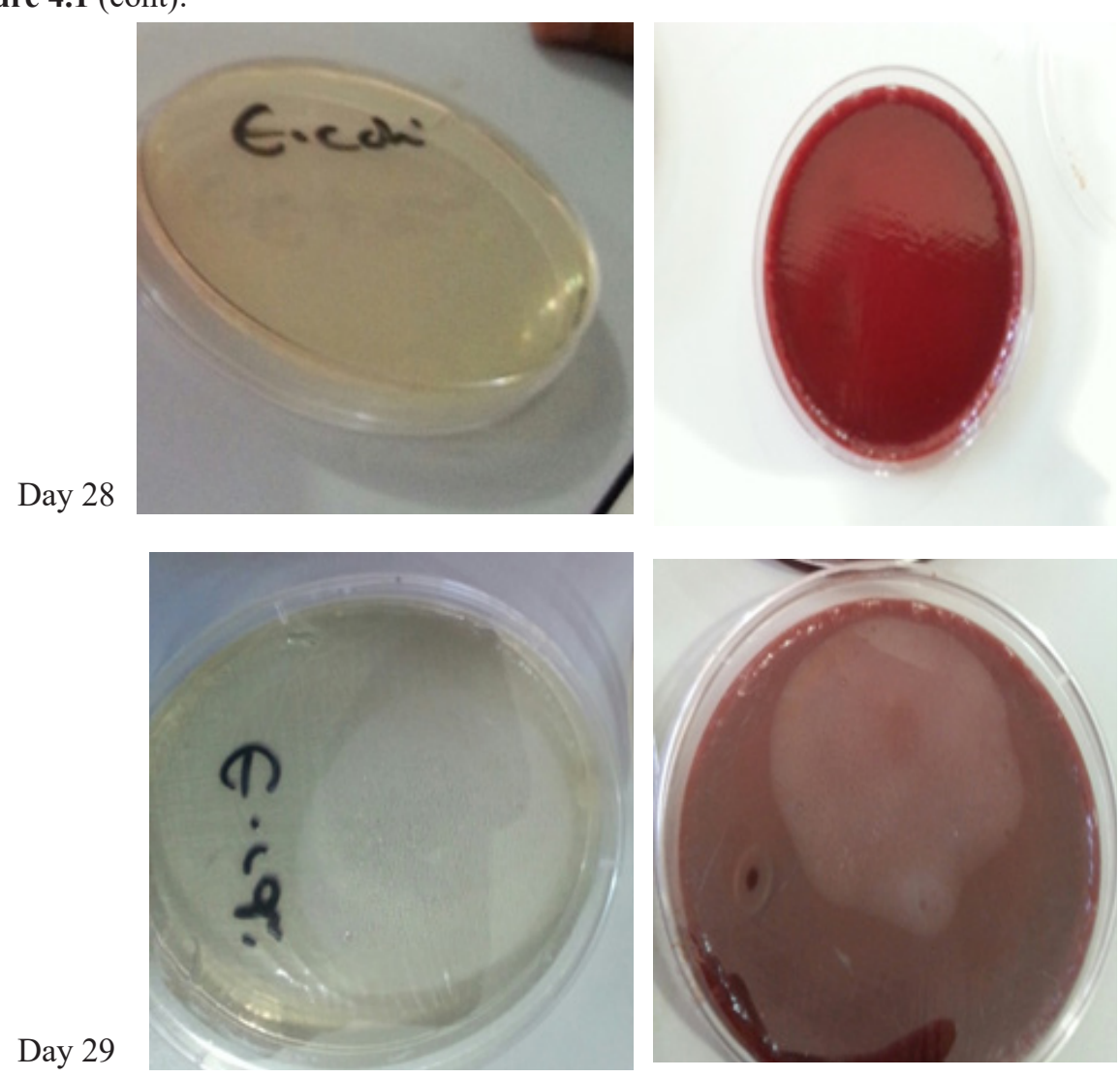

\section{Note:}

E.coli was cultured into two different media, nutrient agar and blood agar which is more rich for bacteria growth.

Culture showed there is no growth during all 28 days from opening the eye drops, but after 28 days bacterial growth was observed.

Figure 4.2 Effectiveness of preservative on S.aureus :
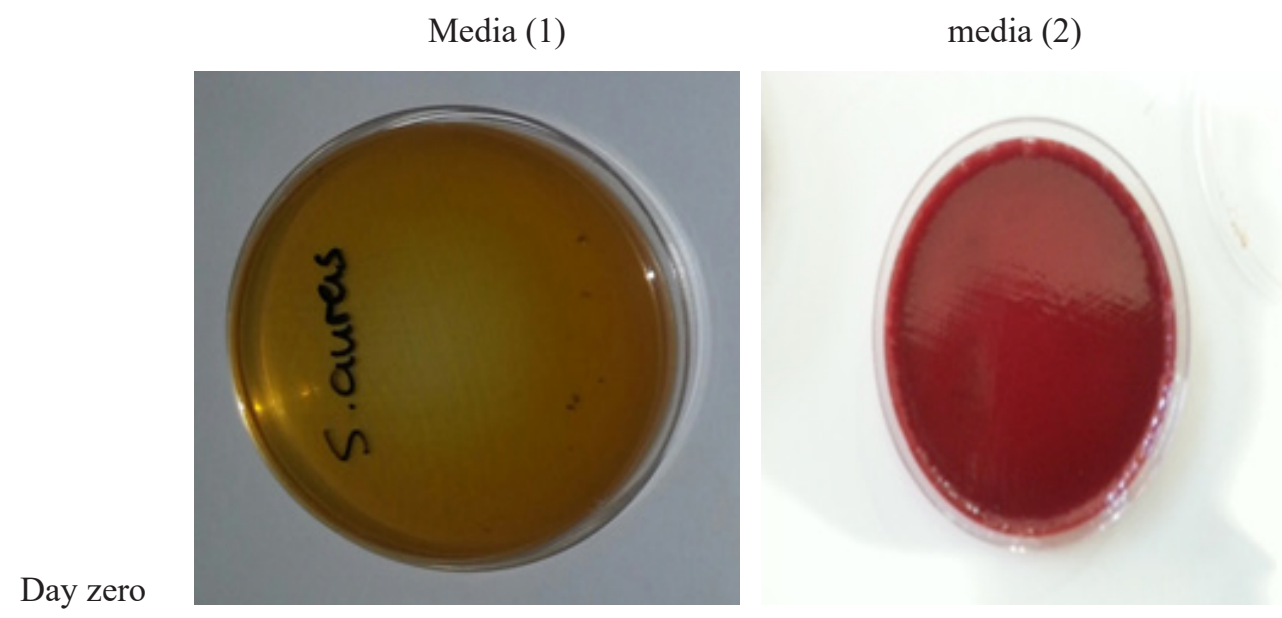

International Journal of Pharma Sciences and Scientific Research An open Access Journal 
Day seven
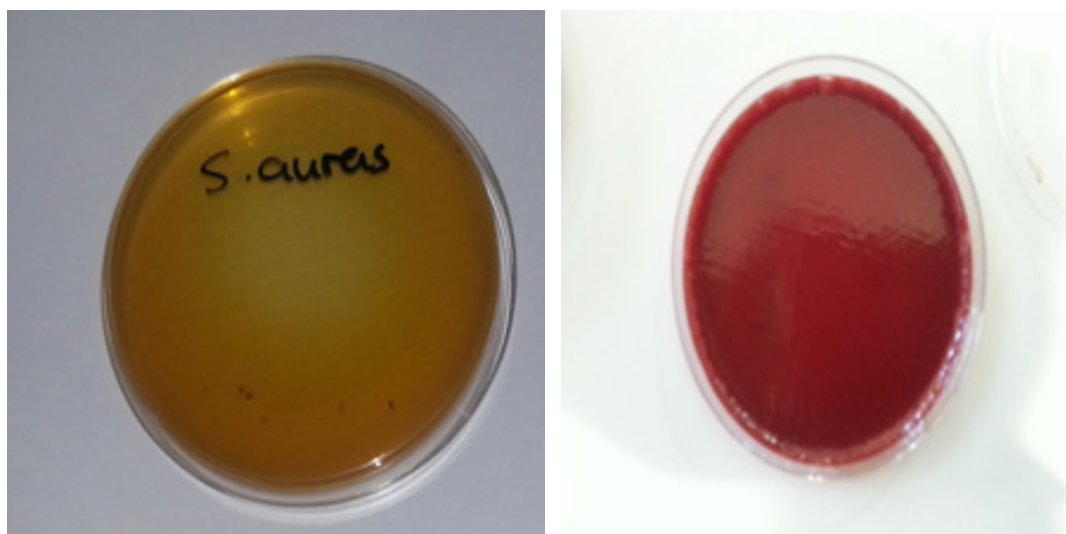

Day 14
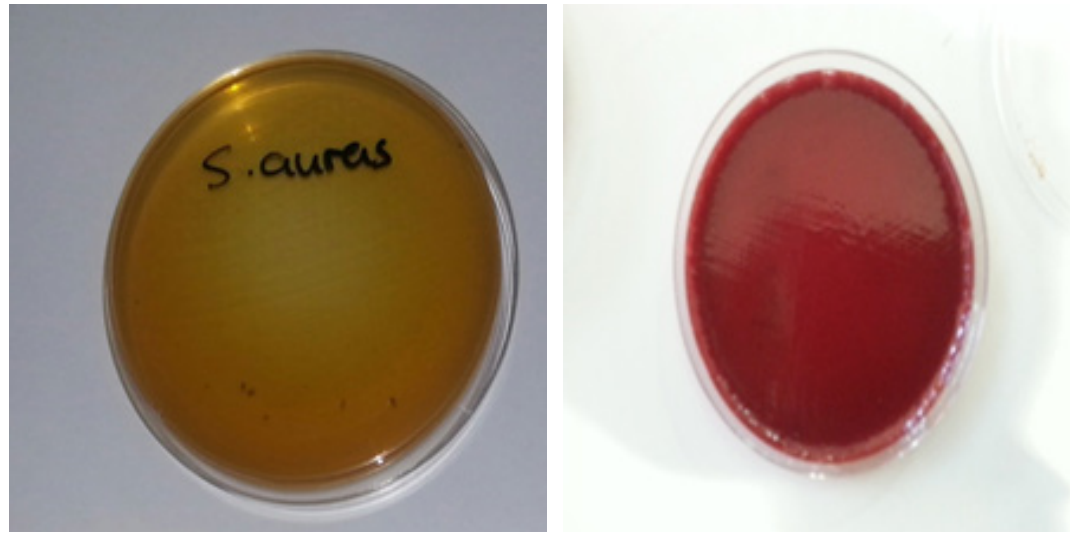

Figure 4.2 (cont)

Day 28
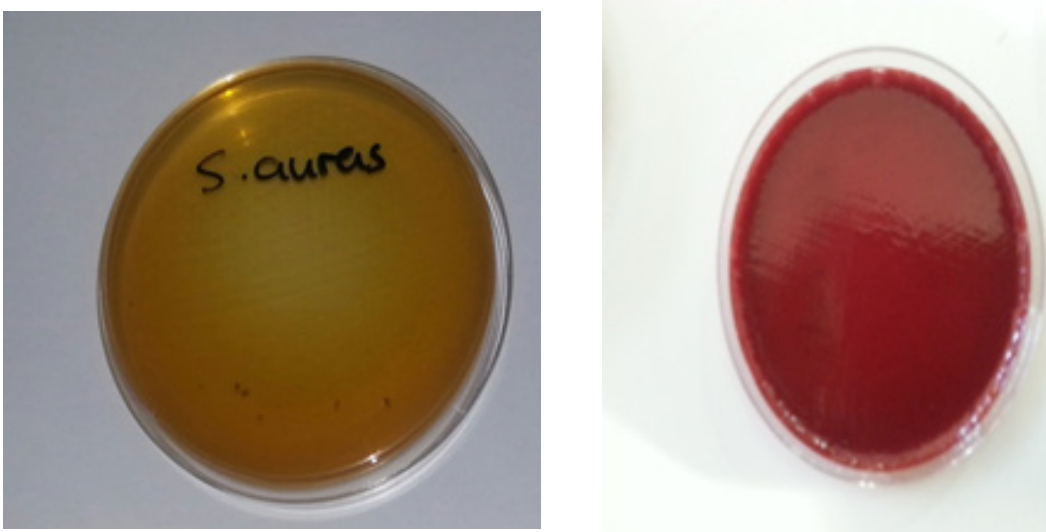

International Journal of Pharma Sciences and Scientific Research An open Access Journal

Volume 2 Issue 4, September 2016 


\section{Day 29}
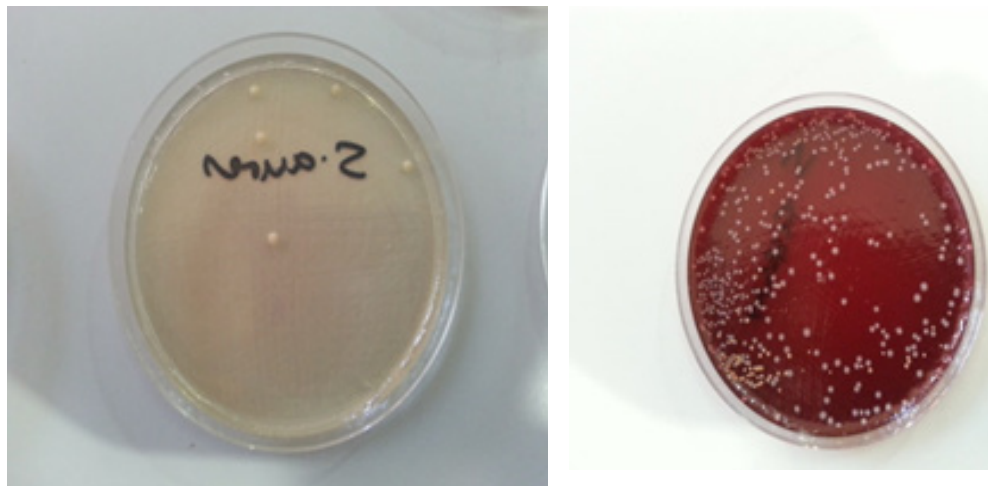

\section{Note:}

S.aureus was cultured into two different media, nutrient agar and blood agar which is more rich for bacteria growth. Culture showed there is no growth during all 28 days from opening the eye drops, but after 28 days bacterial growth was observed.

Figure 4.3 Effectiveness of preservative on P.aeruginosa:

Media (1)

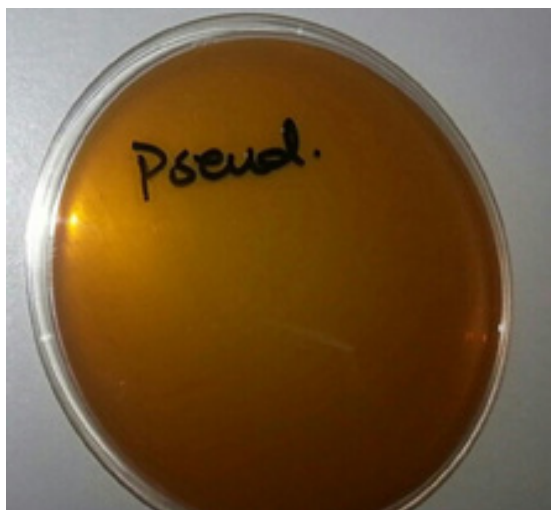

Day Zero

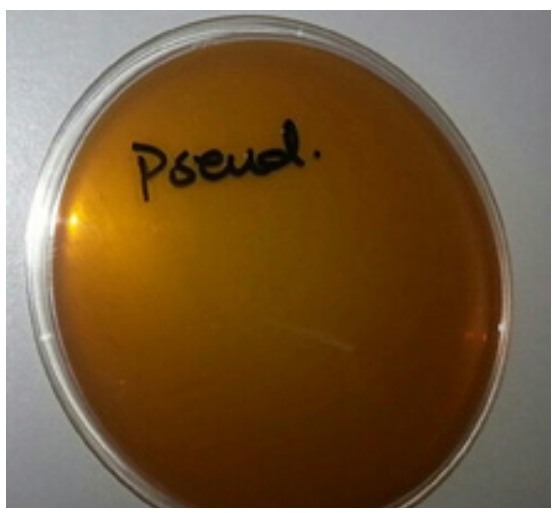

Media (2)
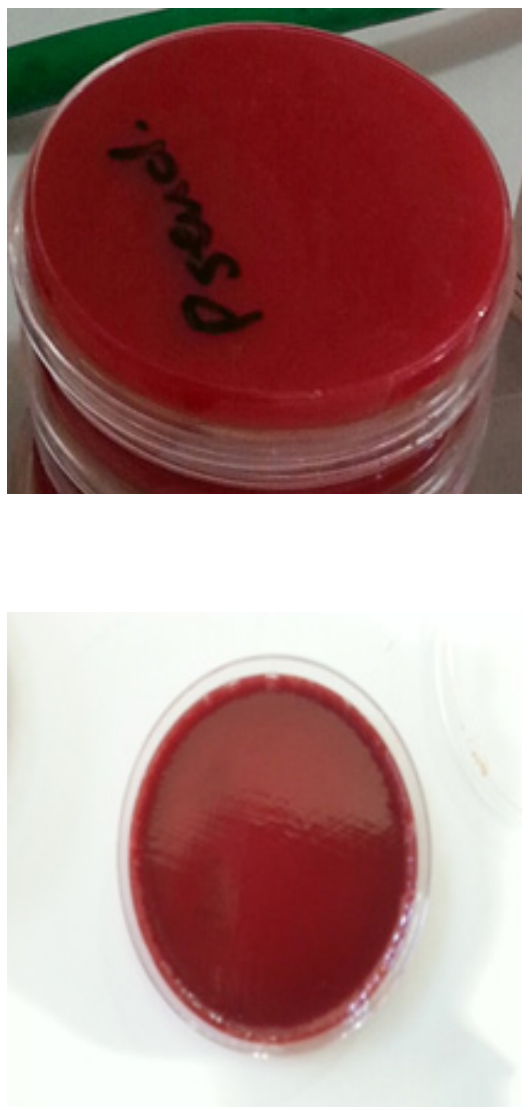
Day 14
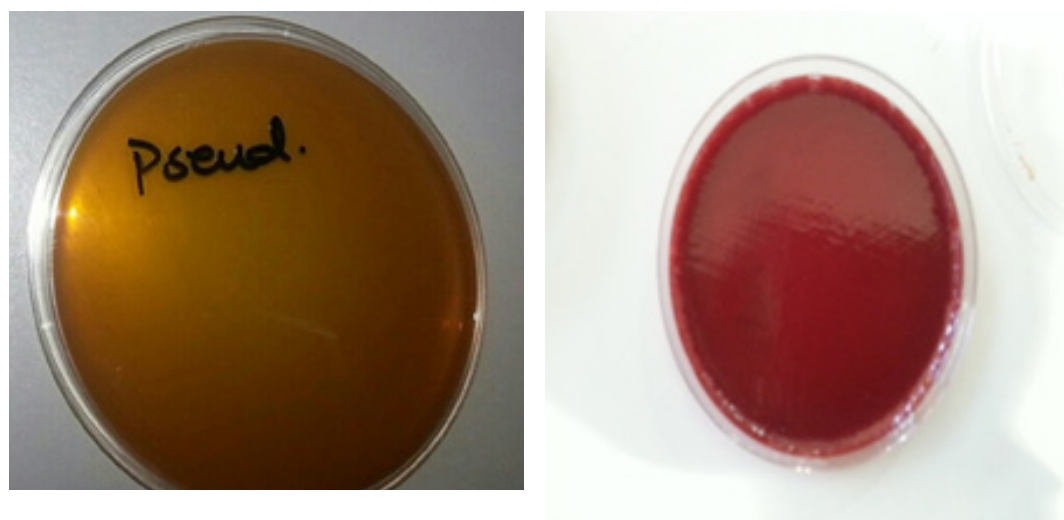

Figure 4.3(cont):

Day 28
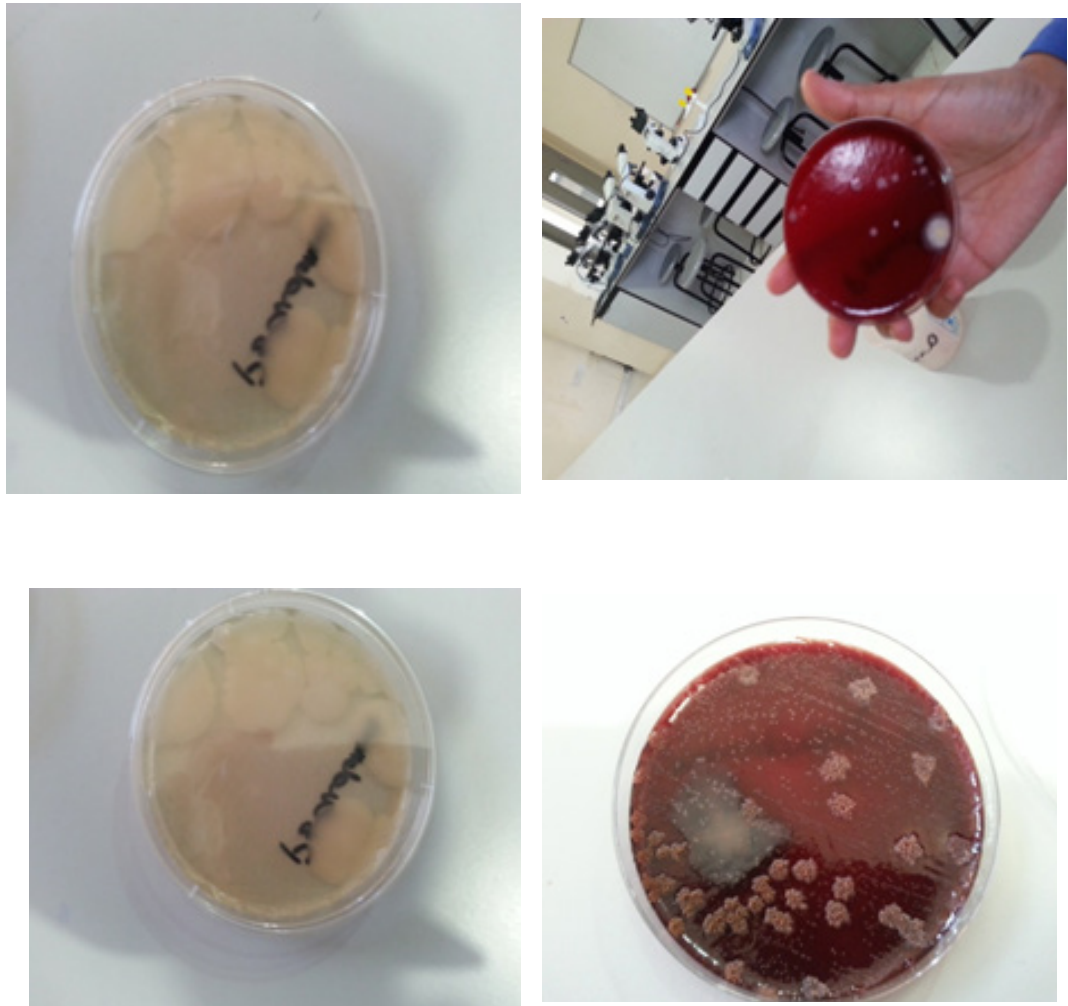

Day 29

Note:

P.aeruginosa was cultured into two different media, nutrient agar and blood agar which is more rich for bacteria growth.

Culture showed there is no growth during all 28 days from opening the eye drops. But after 28 days bacterial growth was observed. 
Figure 4.4 Effectiveness of preservative on Candida:
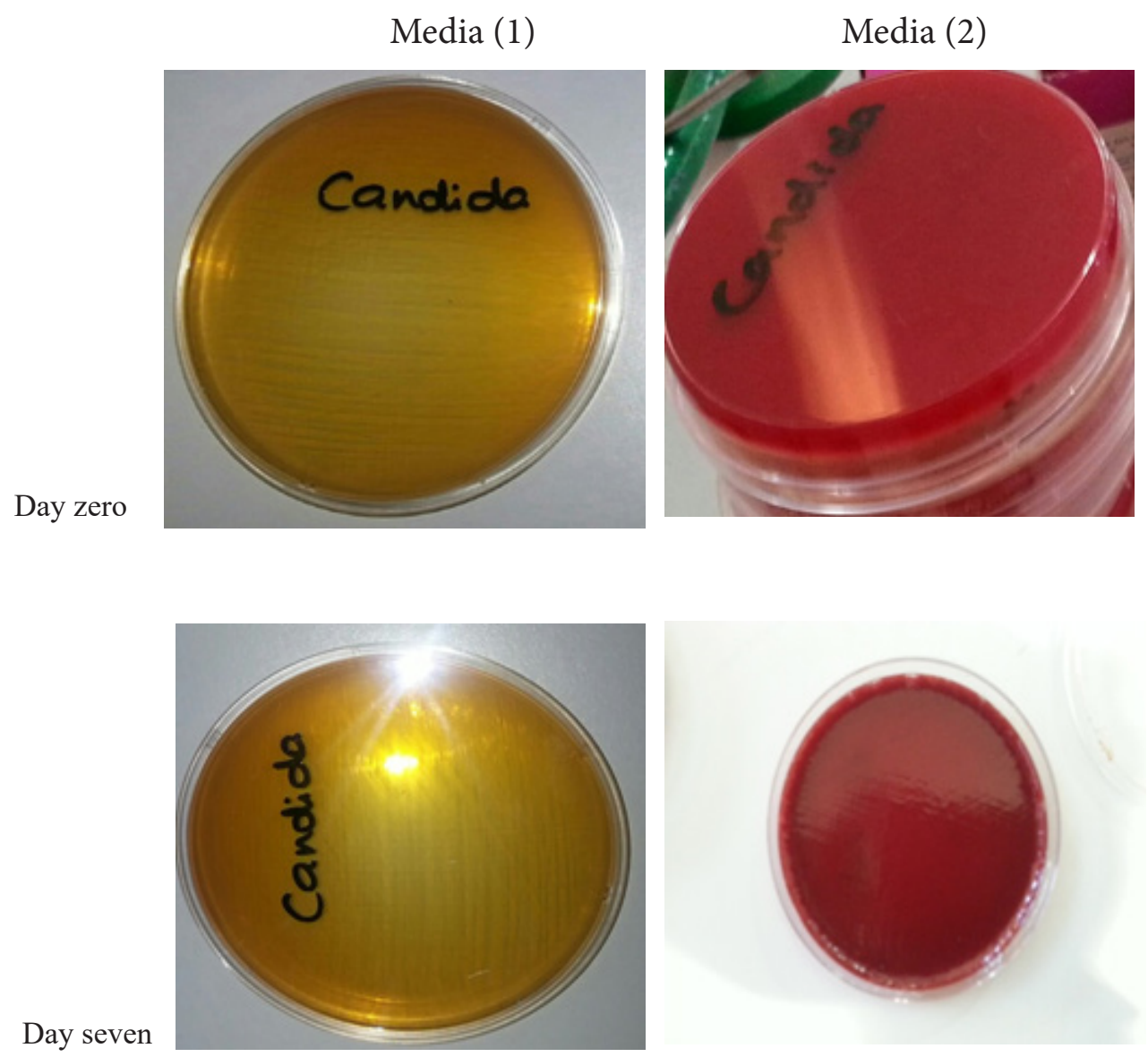

Day 14
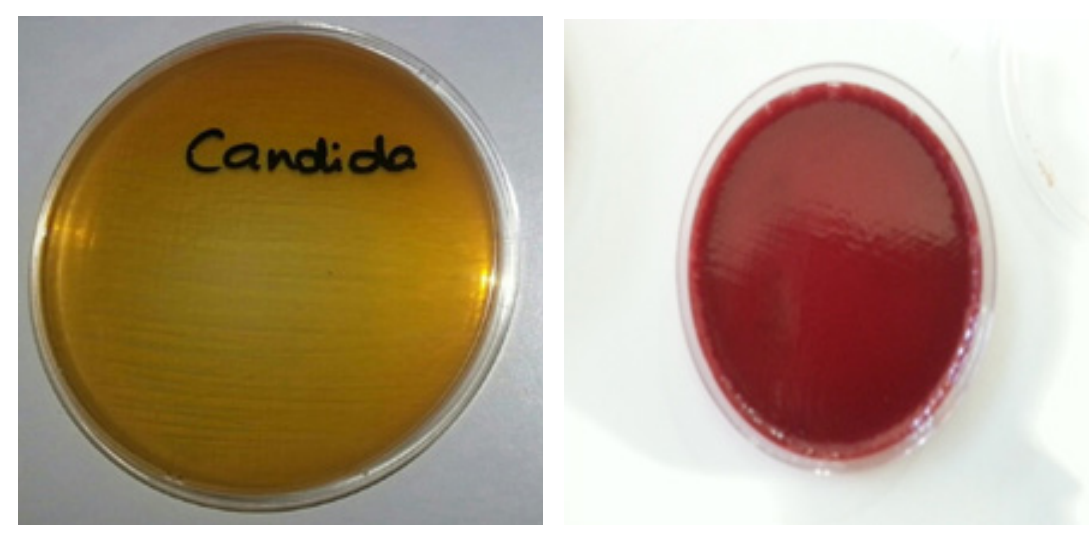
Day 28
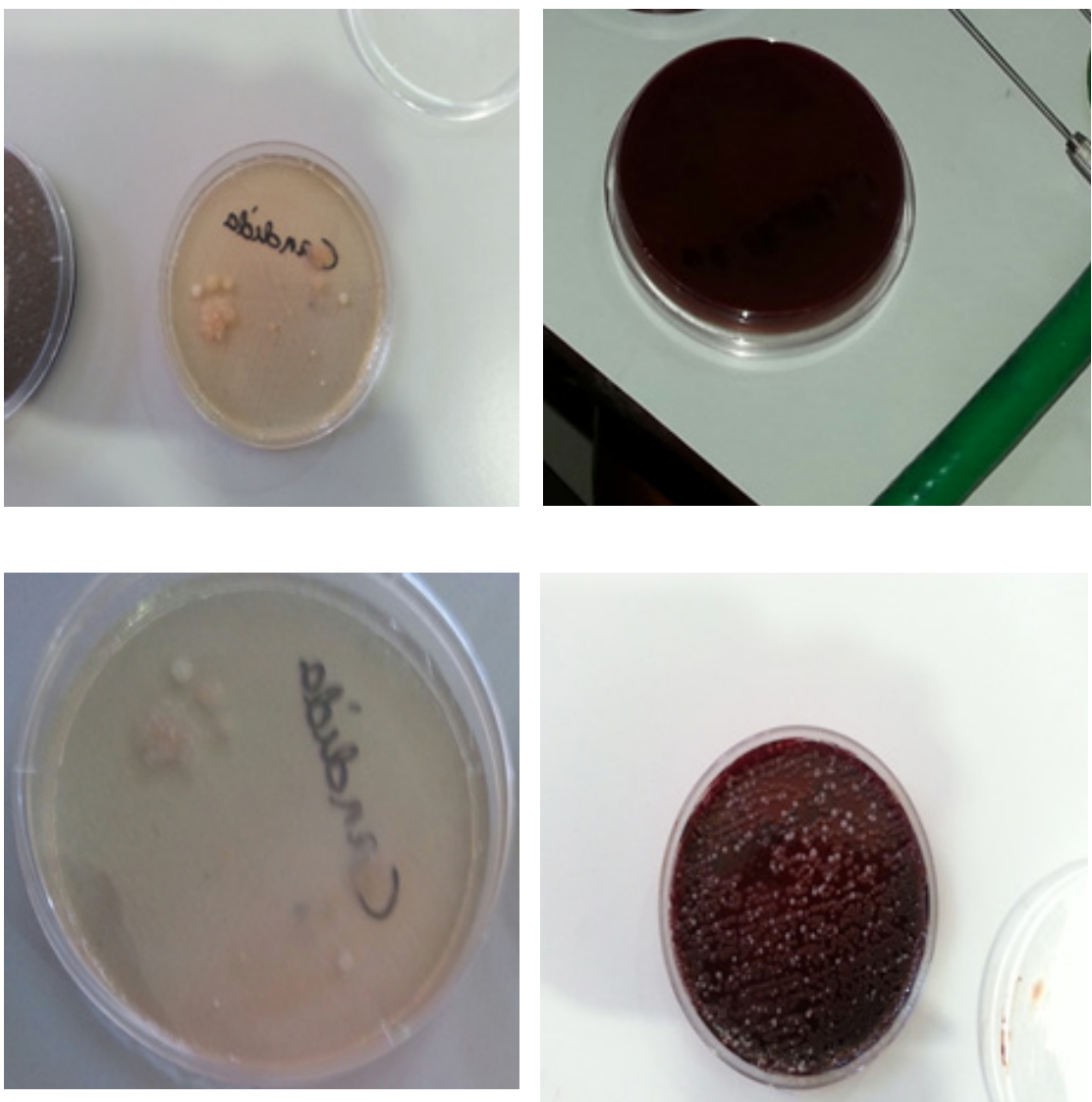

Note:

The culture of the Candida was made on 2 different media, nutrient agar and blood agar which is more rich for bacteria growth.

Culture showed there is no growth during all 28 days from opening the eye drops. But after 28 days bacterial growth was observed.

Table 4.10: $\mathrm{pH}$ determination:

\begin{tabular}{|l|l|}
\hline Analysis days & $\mathbf{p H}$ \\
\hline Day zero & Be comply \\
\hline Day seven & Be comply \\
\hline Day 14 & Be comply \\
\hline Day 28 & Be comply \\
\hline After 28 day & Not comply \\
\hline
\end{tabular}


Table4.11: result of $\mathrm{pH}$

\begin{tabular}{|l|l|}
\hline Analysis days & $\mathbf{p H}$ \\
\hline Day zero & 6.7 \\
\hline Day seven & 6.7 \\
\hline Day 14 & 6.8 \\
\hline Day 28 & 7 \\
\hline After 28 day & 7.7 \\
\hline
\end{tabular}

In agreement with the results already obtained on the compliance of the product to API contents and preservative effectiveness, the $\mathrm{pH}$ results conducted fall within the stated official range up to the 28th day after container opening. Beyond that day the product become out of $\mathrm{pH}$ range .

there to prevent infection in the eye but just to maintain sterility of the bottle against microbes (viruses, bacteria, and fungi or molds). But are they really effective in doing so? Some studies indicate that preservatives do not protect against all types of possible contamination of the bottle. Quartenary ammoniums have a limited efficacy against some gram positive and negative bacteria but particluarly against some mould spores such as mycobacteria and clostridium for instance[1,2].

One study found that $29 \%$ of solutions were contaminated by microorganisms[4]. Another study done in ophthalmic consultations services and in a home for the elderly [though usually trained in hygienic measures], demonstrated that $16.3 \%$ of all bottles were contaminated, including $5.4 \%$ very severely contaminated [5].

Another study on a broad range of preservatives, concluded that only the combination of Benzalkonium and EDTA was able to meet the safety criteria for European Pharmacopoeia[4]. But this combination is also one of the worst for the eye's heatlh .

Specification for the eye drops ensure BP\USP general requirements for eye drops are met and include requirments for :

Percent content of the active ingredints, potency of each active ,limit of degradation related to each active , $\mathrm{pH}$, sterility and preservative efficacy .

The aim of this study is to determine the efficiency of preservative in multi dose timolol eye drops and to determine the magnitude and pattern of microbial contamination .

The test is counducted in accordance with British Pharmacopoeia and US Pharmacopoeia

Antimicrobial preservatives are added to products to prevent or limit microbial contamination, which can occur during normal conditions of storage and use. The efficacy of an antimicrobial preservative may be enhanced or diminished by the active constituent of the preparation, or by the formulation in which it is incorporated, or by the container and/or closure being used as the final packaging material.

The test used was qualified for the product under evaluation, and correct dilution was used in assays for surviving microorganisms.

The product is inoculated with specified number of each challenge organism. The inoculated product is held at room temperature for 28 days. It is examined by the duplicate plate count method to determine the number of viable microorganisms which survive at each specified time interval.

All results are evaluated in accordance with the tabulated acceptance criteria of the relevant Pharmacopoeia's or test protocols.

The benzalkonium chloride added to the timolol eye drops under study, was found to be effective until 28 days after opening the eye drops and cause complete reduction to all microorganism and this result was found to comply with BP and USP specification limit. Accordingly the drops can be safely used all over this period and discard after 28 days.

A confirmation test was done to investigate microbial growth after 28 day . One day after 28 days culture was found to give huge growth of bacteria and Candida that are even not countable ( $>300$ cfu $\backslash \mathrm{ml})$. This indicates that the preservative loses its efficiency after 28 days.

Another specific objective of the study is to investigate the percent content of the active ingredient of the timolol eye drops and to see if it's complying with label and meet the requirements and specification of manufacturer and BP.

The study indicated that the percent content complied with label and is within the specified range.

For days zero, seven and fourteen, the preparation complied with requirements and percent content was found to be $96 \%, 98 \%, 100$ $\%$ respectively.

Day 28 and one day after the 28th day the drugs were found to be not complying with specification and these prove that the drug should be discarded after 28 days and should be consider as unsafe for use.

The reason why it's recommended to discard eye drops after 28 days is for sterility reasons. After a bottle of eye drops is opened, bacteria and fungi might be able to get into the bottle and grow, which may lead to serious eye infections.

Also one of the specific objectives of this study is to determine the compliance with respect to acidity and alkalinity.

The results obtained showed that the preparation is complying with the specification limit, but one day after the 28 days noncompliance was observed. The results were out of the specified range with a $\mathrm{pH}$ value of 7.7. This $\mathrm{pH}$ value promotes good environments for bacterial growth. 
This gives an addition proof that the eye drops should be discarded after 28 days from date of opening of container.

\section{Conclusion:}

Medicines and drugs given to the patient should be stable physically, chemically and microbiologically throughout their shelf life and during use.

Analysis should be done to ensure safety and quality for all medicines in any form of dosage form.

Ophthalmic eye drops are sterile dosage forms, disposal recommended after 28 days from opening the eye drops, because of high susceptibility to bacterial contamination which may lead to serious eye infection.

During and after manufacturing antimicrobial effectiveness test should be done to ensure the efficiency of the preservative during the period of use.

Also other test for evaluation of the eye drops should be done e.g. sterility, $\mathrm{pH}$, preservative efficiency and percent content of API.

Recommendation:

- More researches should be done in this area to ensure safety and quality for all the sterile dosage forms not the eye drops only.

-Antimicrobial effectiveness test should considered as routine test in all quality control labs and should be conducted to ensure efficiency for all drug categories (sterile dosage forms, injections, and other parenterals including emulsions, otic products, sterile nasal products, and ophthalmic products made with aqueous bases or vehicles.

- It is necessary to retest the effectiveness of the preservative system any time the formulation is changed or when significant product or packaging change occurs.

- Preservative reference standard should be provided for chemical assay by HPLC or other spectroscopic method for analysis to ensure compliance with specification.

\section{Reference:}

1. ICH. 2004. Guidance for Industry - Q1F Stability Data Package for Registration Applications in Climatic Zones III and IV

2. Moldenhauer, J and Sutton SVW. 2004. Towards an Improved
Sterility Test. PDA J Pharm Sci Tech. 58(6):284-286.

3. Cundell, AM. 2004. Microbial Testing In Support of Aseptic Processing. Pharm Technol. 28(6):58-66.

4. Parfitt ,K ."Martindale: The Complete Drug Reference” 32 nd Ed., Pharmaceutical Press, Massachusts (1999).

5. WHO pharmacopoeia libarary .apps.who.int $\backslash$ phintlenlp $\backslash$ docf

6. Boyce, M. C. Electrophoresis. 22 , 1447 (2001).

7. Hang, H. Y. Lai, Y. C. Chiu, C. W. Yeh, J. M. Chromatogr. 993 , 153 (2003)

8. Preservative in eye drops. Acta Ophthalmological Volume 47, Issue 3, June 1969, Pages: 461-475, R. BARKMAN, M. GERMANIS, G. KARPE and A.-S. MALMBORG Article first published online: 27 MAY 2009, DOI: 10.1111/j.1755-3768.1969. tb08132.x

9. An evaluation of chemical preservative for ophthalmic solution. Journal of the American Pharmaceutical Association

Volume 44, Issue 8, August 1955, Pages: 457-464, C. A. Lawrence,Article first published online: 27 SEP 2006, DOI: 10.1002/jps.3030440802

10. Antimicrobial activity of benzalkonium chloride in potential contact lens fluids Jira T, Panzig B, Pohloudek-Fabini R. Pharmazie. 1982 Aug;37(8):587-90. German. PMID:7146068 [PubMed - indexed for MEDLINE]

11. Antimicrobial Activity of a New Preservative for Multiuse Ophthalmic SolutionsGhelardi E, Celandroni F, Gueye SA, Salvetti S, Campa M, Senesi S.

J Ocul Pharmacol Ther. 2013 Feb 21. [Epub ahead of print] PMID: 23428175 [PubMed - as supplied by publisher]

12. Preservatives in ophthalmology , Messmer EM. Ophthalmologe. 2012 Nov;109(11):1064-70. doi: 10.1007/s00347-012-2638-4 German. PMID: 23179809 [PubMed - in process]

13. The United States Pharmacopeial Convention, Inc., The United States Pharmacopeia, 18th Revision, (1970), P.845 Rockville,MD. 